\title{
«El Día de Dios». Acerca del tiempo, según Franz Rosenzweig
}

«The Day of God». On Time, according to Franz Rosenzweig

\author{
Esteban J. Beltrán Ulate \\ Universidad de Costa Rica, Costa Rica \\ estebanbeltran@outlook.com \\ Recibido: 06/01/2016 • Aceptado: 27/03/2017
}

\begin{abstract}
Resumen
Abstract

Este artículo acomete el análisis de la concepción de temporalidad desarrollada por el filósofo alemán Franz Rosenzweig (1886-1929), a partir del escrutinio de su principal obra Der Stern der Erlösung (1921), desde una perspectiva fenomenológica. El tiempo, ahí, se comprende en una tridimensionalidad, a la luz de la noción del «Día de Dios». El planteamiento del pensador judío evidencia una ruptura con las tesis filosóficas modernas, que presentan el tiempo como absoluto. En oposición a esta creencia, establece una relación entre redención e historia del mundo, donde la eternidad comprende, en su estructura, pasado, presente y futuro. En la primera parte, se expondrá una breve semblanza del casselense. A continuación, se presenta una exposición de la tradición judía sobre el tiempo, de la que se deriva una crítica a su concepción moderna. A continuación, se expone la doctrina sobre el tiempo que presenta La estrella de la redención y, finalmente, se concluye
\end{abstract}


mostrando la relación entre temporali- showing the relation between temporaldad y eternidad como la expuso Franz ity and eternity as understood by Franz Rosenzweig.

Rosenzweig.

Palabras clave: día de Dios, eternidad,

Keywords: Day of God, eternity,

Fenomenología del tiempo,

redemption, time, Phenomenology

redención, tiempo.

of Time. 
“y ha puesto eternidad en el corazón de ellos, sin que alcance el hombre a entender la obra que ha hecho".

Qohelet, 3, 11

\section{Palabras preliminares}

En este artículo se acomete un análisis de carácter introductorio de la concepción de temporalidad desarrollada por el filósofo alemán Franz Rosenzweig (1886-1929), a partir del escrutinio de su principal obra Der Stern der Erlösung (1921). Para el casselense, el tiempo se comprende en una tridimensionalidad, a la luz de la noción «Día de Dios». Durante el desarrollo de la pesquisa se evidencia una ruptura de Rosenzweig con las tesis filosóficas modernas, que presentan el tiempo como absoluto. En oposición a esta concepción, Rosenzweig establece una relación entre redención e historia del mundo, donde la eternidad se comprende en su estructura pasado, presente y futuro.

Rosenzweig, con su autodenominado «nuevo pensamiento», refutó las posturas totalizantes de la filosofía moderna y, sin desligarse de su concepción teológica, asumió una lectura filosófica del mundo. El autor recibió una influencia de la obra de Hermann Cohen, de cuya doctrina se desprendió conforme su pensamiento adquirió madurez. El «nuevo pensamiento» del casselense se volvió un punto de referencia para una serie de pensadores del siglo XX, tales como Walter Benjamin y Emmanuel Lévinas. En esto radica la importancia de traer a colación el aporte a la fenomenología del tiempo de uno de los filósofos más influyentes en el pensamiento filosófico con tintes judíos de inicios del siglo XX. 
Rosenzweig: la figura

Franz Rosenzweig nació en Kassel el 25 de diciembre de 1886. En su juventud, optó por cambiar sus estudios en medicina por los de filosofía. En 1908, en Friburgo, trabajó en una tesis doctoral titulada Hegel y el Estado, que lo aproximó al conocimiento del idealismo alemán. En esta época, titubeó respecto de su fe y coqueteó con la idea de convertirse al cristianismo, como lo hiciera su primo Eugen Rosentock. No obstante, durante, el Yom Kippur del año 1913 (según calendario gregoriano), se reincorporó a la tradición judía e, inspirado por los seminarios del neokantiano Hermann Cohen, de quien ha sido considerado su heredero, logró madurar en su pensamiento lo que se ve reflejado en diversas correspondencias y en su obra principal, La estrella de la redención (1921). Falleció el 10 de diciembre de 1929, luego de un proceso de ocho años en el cual sus facultades físicas fueron aminorando debido a una esclerosis lateral amiotrófica, que le imposibilitó movilizarse, hablar e incluso escribir.

El casseliano, una vez finiquitados sus estudios sobre Hegel, se convirtió en su impugnador, y encontró valiosas líneas para el desarrollo de sus ideas en autores como Schelling, Kant o Hermann Cohen, como él mismo menciona en la correspondencia con su madre, el 15 de abril de 1918: "soy realmente anti-hegeliano (y anti-fichtiano); y mis santos patrones... son Kant y -sobre todo- Schelling” (Bertolino, 2000: 257-287).

Rosenzweig ha sido considerado como un referente del pensamiento judío. Incluso es reputado por García Baró "el más grande pensador judío desde los tiempos de Espinosa hasta la Catástrofe" (García Baró en Rosenzweig, 2006: p.11), en la introducción a la versión castellana de La estrella. Por su parte, Walter Benjamin llegó a tenerlo por "uno de los grandes trabajos de la academia alemana" (Toscano, 2014: 54, citando a Benjamin, 1991). Gershom Scholem lo consideró una de las más sublimes manifestaciones religiosas de grandeza y genio del pueblo judío (Lucca, 2012). Uno de los principales herederos de su obra, Emmanuel Lévinas, lo tiene demasiado presente como para citarlo. Así lo advierte en el prefacio de su obra Totalidad e Infinito (2016: 22). 
Más allá de las guías para la elaboración de su «nuevo pensamiento», Rosenzweig se encontró, o re-encontró, con la tradición judía, que es la que le permitió esclarecer su metodología.

\section{El tiempo en la tradición}

Desde la Antigüedad, la tradición judía ha delineado la concepción del tiempo, alejándose de ritos religiosos de carácter cíclico y postulando una comprensión del tiempo como una configuración irreversible. Esta irreversibilidad se hace tangible en una serie de manifestaciones necesarias, producto de la voluntad divina, que irrumpe en la historia para incidir en el tiempo del mundo. La novedad judía, frente al pensamiento prototípico antiguo, se desvela con esta irrupción en el tiempo del mundo por parte de la divinidad. Un ejemplo de esta intrusión se comprende por conducto de la catástrofe, que es capaz de sancionar, educar e, incluso, emancipar al pueblo con el objeto de encaminarlo.

A diferencia de otras tradiciones antiguas, donde las deidades obviaban al hombre o lo asumían de manera esquiva, el judaísmo presenta al ser humano con un rol preponderante respecto a Dios. En el judaísmo, solamente hay un Dios y su creación, tal como se expresa en el libro del Bereshit: el hombre es su imagen y semejanza, por ende, la irrupción divina en el tiempo del mundo resulta necesaria, y es constante, por su condición de diálogo perpetuo.

Lejos de las diversas culturas antiguas con las que convivió el judaísmo, la propuesta del tiempo planteada por éste se distingue en cuanto al carácter de irrupción-diferencia-otredad. Mientras que, en algunas tradiciones distintas al judaísmo se atiende a un modo de vida de carácter cíclico, el judío se constituye como un pueblo que, constantemente, se ve interpelado por irreversibilidades, como producto de la intervención divina. Este diálogo diacrónico configura el modo de vida del pueblo, como indica Toscano: "los judíos fueron los primeros en descubrir la significación de la historia (pasado) como epifanía de Dios: incidencia de la divinidad en el tiempo del mundo" (2014: 56). 
Las irreversibilidades de la Historia son instantes que se vinculan entre sí, permitiendo una mirada trans-histórica del pueblo. Un ejemplo claro se desvela con la ruptura de la tradición paleo-semita, ilustrada por el relato del sacrificio irrealizado del hijo de Abraham, Isaac, donde el designio divino quebranta el mandato de la muerte del hijo primogénito: "Sacrifice of this first child restore to the divinity what belonged to him" (Eliade, 1954: 109). ${ }^{1}$ La tradición judía es una muestra de la diferencia que se presenta en la configuración histórica: quebranta el modelo cíclico del tiempo y asume una concepción de tiempo como aquello que repite, en diferencia. Otra forma de analizar lo anterior sería comprender que la temporalidad, como modelo sincrónico del modo de vida del mundo, contiene una serie de ciclos, constantemente reiterados, pero que se renuevan a partir de las diferencias que irrumpen como tales en el día del mundo.

El orden cíclico de la temporalidad del mundo se ve intersecada y abruptamente desviada, constantemente; la eternidad se inserta en la temporalidad e instaura una nueva configuración en una comunidad que se torna «trans-histórica». Esta irrupción irreversible es acrónica, por lo que se torna como afirmación fundacional, que continúa renovando y renovándose en el pueblo a través de los tiempos.

La otredad del tiempo se descubre, así, en la tradición, como acto eternizador que transgrede la sincronicidad del tiempo del mundo, instantes que se asoman en el día del mundo. Lo anterior es ilustrado en la explicación que brinda Maimónedes en la Guía de Perplejos (Moré nebukim) al referirse a la institución del Shabbat. En este caso, RaMBaM Anesher Hagadol («el Gran Águila») expresa cómo el Shabbat es un instante que se configura de doble manera. En primer lugar, como el descanso posterior a los seis días de la creación y, en segundo lugar, como el memorial del éxodo de Egipto, como acto de liberación ante la esclavitud (Taub, 2011). Esto evidencia cómo, en el Shabbat, se desvela un instante que vincula irreversibilidades que irrumpieron y que son asumidas como nuevas, configurando el carácter del pueblo.

1 “El sacrificio de este niño restaura a la divinidad lo que le pertenecía" [Trad. del autor]. 
Constantemente, el judaísmo vive una anticipación de la redención de manera colectiva y trans-histórica, participando de la eternidad, de la otredad del tiempo. Esto lo retoma Rosenzweig, tal como lo expone Toscano (2004), en referencia al texto "El país de los dos ríos" (Zweistromland), que cita: "[lo] que ha hecho Dios, lo que hace, lo que hará, lo que le ha sucedido al mundo, lo que le sucederá, lo que le ha sucedido al hombre, lo que le sucederá -es imposible separar todo eso de su temporalidad” (Toscano, 2014: 62, citando a Rosenzweig, 2001: 221-223).

La estrella de la redención es una obra que asume la temporalidad desde y con la voz de la tradición que confuta a la conciencia idealista. Rosenzweig parte de la tradición teológica judía y se abre a una novedosa interpretación, donde despunta su concepción del Día del Señor.

Crítica a los planteos de la Modernidad

En su obra El nuevo pensamiento (Das neue Denken, 1925), Rosenzweig esgrime una distinción entre lo que considera como «nuevo pensamiento»y «pensamiento anterior». Según su caracterización, el pensamiento anterior resulta: lógico, atemporal, autosuficiente y tematiza el mundo de manera substancial; mientras que el pensamiento nuevo es gramático, enlazado al tiempo, dialógico, manifiesta un mundo no tematizado sino comprendido como relacionalidad, siguiendo a Toscano (2014).

Lo que el autor caracteriza como pensamiento anterior está constituido por la filosofía de la totalidad, construida desde Jonia hasta Jena, de Parménides a Hegel, a lo largo de tres bloques ilustrados, que se reconocen en la filosofía de la Antigüedad, la filosofía del Renacimiento y la filosofía de la Modernidad.

Para Rosenzweig, la Historia de la filosofía se encuentra en completa coincidencia con la dinastía del idealismo, idealismo que vio su tarea consumada en el siglo XIX bajo la consigna de conocer la totalidad, pensándola, por lo que al comprenderse la razón a sí misma histórica, se cierra sobre sí en su sistema, según lo expone en $L a$ 
Estrella. Mas semejante culminación del pensamiento en el hegeliano tiene su origen en el culto al Ser parmenídeo. Rosenzweig, con influjo nietzscheano, procura socavar la tradición desde la base, ya que concibe que la pregunta no subyace en cómo el ser ha sido, sino en cómo el ser se ha manifestado.

Así, pues, frente al itinerario parmenídeo del ser como única vía de investigación que permite una correspondencia entre lo real y lo pensable, Rosenzweig reacciona y, rebate al eleata a propósito de la imposibilidad de que la nada sea o que se derive algo de ella, precisamente afirmando que el ser procede de la nada una y universal: "De la nada mana, pues, sin fin la Esencia y, en clara delimitación respecto de ello, el Acto rompe la nada" (Rosenzweig, 2006: 64).

Rosenzweig, a partir de la nada coheniana y con el martillo nietzscheano, rompió con el planteamiento parmenídeo y anunció la caída de los ídolos de la Modernidad, erigidos al abrigo del ser. El casseliano deconstruyó las categorías occidentales que han postulado una filosofía de la totalidad, dinastía de dos milenios que encuentra origen en Tales y Parménides y su culminación en Hegel.

En Hegel, culmina el itinerario del ser como totalidad pensable. Contra Hegel y a la luz de una interpretación metafórica de un relato del Bereshit, Rosenzweig muestra el contraste entre Esaú y Jacob: el primero busca asentarse en la tierra, gobernar bajo un criterio de ordenanza y dominio temporal; en tanto que Jacob, sin dejar su carácter de nómada, con una apertura incesante hacia el porvenir, atiende a un llamado siempre otro, que no puede tematizar. Por su parte, Rosenzweig burla el ser como fundamento y, desde la nada del conocer, atiende a la otredad que habita en las tierras extranjeras de la totalidad. Rosenzweig concibe una serie de rendijas en la totalidad, como grietas en el techo por donde cruza la luz.

Por su parte, el idealismo es una catástrofe, en tanto comprime la realidad a lo pensado y reduce el decir a lo dicho. El idealismo se entrega por completo al poder de la lógica, que pasó de ser su artefacto a ser su amo y señor. En manos de la lógica, se ha orquestado una pérdida de confianza en el lenguaje. Esto plantea un desgarro de la realidad. Pero, en la condición trans-histórica del judaísmo que anticipa la eternidad, se evidencia la imposibilidad de la totalidad 
histórica, como afirma Balcarce (2010). Una vez alcanzada una total objetivación de la realidad, existe un resto que no logra ser tematizado y que no logra ser asumido dentro del plan de la totalización del ser pensado.

La refutación del idealismo por parte del autor de La estrella es categórica. Denota un enfrenamiento al atrevido plan omnicomprensivo de la escuela idealista, ya que éste ha devenido una tiranía. Sin embargo, en la existencia la muerte acontece como una voz infranqueable que, desde lo incomprensible, golpea las puestas de la razón, como expresa Luca Bertolino:

El pecado original del idealismo es haber querido olvidar la muerte y la finitud del individuo, para dirigir sus pensamientos a la totalidad donde desaparece el individuo con sus limitaciones... De ahí el error de idealismo, que excluye al individuo del mundo, o más bien lo sumerge en el panteísmo del Todo, terminando por reducir la muerte a una mera nada (2000: 257-287).

El anhelo del idealismo, al concebir la razón como triunfo, la supone condición suprema del pensamiento: nada es fuera de la razón. Rosenzweig (2006), a su vez, desde el absoluto «Yo pienso» se deja interpelar, en la frontera-límite de su razonamiento, por un acontecimiento irreductible e inamovible: el «Yo» como «existencia frente a la muerte», inaplazable, ineludible.

El Yo tiene ante sus ojos la muerte de los otros. La muerte del otro le aterra. No en cuanto muerte del otro, sino en tanto que esa otredad bien puede ser la propia, como afirma Rosenzweig en $\mathrm{La}$ estrella: "Porque sólo otros pueden morir, solo como Él, muere el hombre. El Yo no puede pensarse muerto. Su angustia ante la muerte es la angustia de llegar a ser lo que sólo puede ver son sus ojos en los otros muertos: un Él muerto" (Rosenzweig, 2006: 328). La experiencia de la muerte del otro quebranta el Yo absoluto -la muerte es, así, la disfunción eréctil de la razón-. La angustia al asumir que se está condenado a la muerte permite al hombre reconocer su finitud y su condición de mortal. 
Frente a la completa certeza de la muerte, producto de la muerte del otro, el ser finito llega a concebirse como un mero «ser-parala-muerte» (Heidegger, 2012), dueño de su existencia, existencia, sí, o lo que es igual que sí mismo. Este ser como sí mismo está encarcelado en la atmósfera de su existencia, dejando el mundo moral a su espalda; el ser como sí mismo vive a partir de su propio criterio con su propio paradigma ético, cerrado sobre sí, incapaz de relación. No sabe cuál es su origen, no comprende cuál es su porvenir.

Franz Rosenzweig describe la muerte como condición imposibilitadora y afirmadora de finitud. Él concibe que la muerte es, justamente, donde se descubre, a partir del sentido de finitud y mortalidad del ser humano, la experiencia «alógica» (o «metalógica», siguiendo la nomenclatura de Hans Ehrenberg) de la infinitud, de Dios. Si el idealismo procuró, en su itinerario, una tematización de Dios, llegándolo a objetivar de manera absoluta, categorizándolo como objeto de conocimiento del «Yo pienso», la muerte, con su inexorabilidad, golpea las paredes del Yo absoluto, deja entrever el anuncio de la infinitud y anuncia otro modo de ser o un modo de ser más allá de la esencia, más allá de la aparente totalidad.

Allende la concepción hegeliana de lo universal como una y misma esencia de diversas modificaciones, Rosenzweig, siguiendo a Balcarce (2010), atiende a un más allá de la esencia, concebido como otredad, como resto. La nada del conocimiento irrumpe, deja entrever un «incierto», un destello tras el horizonte, hacia lo cual la intuición atiende como llamado. La conciencia intencional corre tras ese resto que se filtra en la totalidad, una alteridad, epifanía que convoca.

En La estrella de la redención se despunta la problemática de la temporalidad idealista, quebrantada, resquebrajada por la irrupción de una revelación que anuncia, que anticipa la eternización. De algún modo, también sigue a su maestro Hermann Cohen, quien asumiere la concepción un más allá que fuese anunciado por los profetas, un más allá que transgrede el aparente futuro sincrónico. Así lo ve el filósofo argentino Emmanuel Taub: "El tiempo mesiánico está siempre llegando, desde el futuro, con la paradójica figura de venir, pero no llegar, ya que realmente es hacia donde se dirige el mundo" (2011: 102). 
Por medio de la exposición de la noción de «revelación»expuesta en La estrella, como anticipación a la «eternidad», plantea la superación de la muerte, y por ende, evidencia la fisura en la concepción de la muerte como una afirmación de la finitud. La estrella plasma la posibilidad de la eternización como acontecer diacrónico, como epifanía, donde lo eterno se presenta en el hoy del mundo; Dios, Mundo y Humanidad, se eternizan como Creación, Revelación, Redención.

La estrella, arquitectura y método

En La estrella de la redención, Rosenzweig asume como punto de partida el no-conocimiento del Dios, del Mundo y del Hombre. Este no-saber-nada, no exime, no obstante, la reflexión sobre estas tres realidades: "Dios es, y es vida siendo. El Mundo es, y es figura espiritualizada. El hombre es, y es sí-mismo solitario” (Rosenzweig, 2006: 125). A pesar de saber que su conocimiento de tales realidades es nada, el itinerario tiene como punto de partida la nada con miras de algo: aceptar la nada de ese algo que acontece como experiencia alógica es el método para acceder a ese algo. Lo planteado por el casselense no es una teoría o teología negativa, sino, más bien, un camino de ascenso, positivo. Desligándose del supuesto del Todo universal, para él la nada no es un abismo oscuro, sino punto de partida del pensamiento.

La triada asumida por el autor (Dios-Mundo-Hombre), mantiene una característica común: el carácter de lo incierto. Son algo así como tres conciencias que solo pueden ser conocidas en su interior a partir de una relación real. Empero, por sí misma, cada realidad no impulsa a la siguiente. No hay una predisposición ontológica que propicie de por sí tal relación. La triple-recíproca-exclusión se verá quebrantada el día mundial y único del Señor: "La ruta de ese movimiento de flujo tiene que originarse en los propios elementos; solo y únicamente en los elementos" (Rosenzweig, 2006: 125). Así, Dios creador, por medio del amor, se revela en el mundo incesantemente y redime al hombre. El día del mundo inicia con la Creación. En su hora última, despunta el día de Dios. 
Rosenzweig concibe que su obra, La estrella de la redención, propicia una lectura distinta del tiempo, expuesto desde un nuevo pensamiento. Su texto no es un mero libro judío o un tratado sobre judaísmo, sino un nuevo sistema de pensamiento, cuyo método es el judaísmo en clave mesiánica. Lejos de ser un texto que incite el desprecio por las otras religiones, asume como punto de partida la tradición judía y, desde sus paradigmas, elabora una propuesta. Así lo expone Putnam en la introducción de la traducción por parte de Nahum Glatzer de la obra de Franz Rosenzweig titulada "Understanding the Sick and the Healthy": "the (anti-) philosophical vision and the religious visión are presented in a beautiful, simple, compelling prose" (1999: 2). ${ }^{2}$

Hay quienes han concebido La estrella como una especie de trabajo en el campo de la fenomenología de la religión. Por su parte, Gersom Scholem ha considerado el texto en su alto influjo místico: "If anybody has ever produced a mystical theory of revelation, it is, in my opinion, Franz Rosenzweig in the second part of the Star of Redemption" (2012: 5). Para el especialista en misticismo y cábala, presenta una fantástica y radical teoría mística de la revelación, a pesar de que, según Scholem, el casseliano no acudiera a la cábala como una fuente directa.

Más allá de estas consideraciones, La estrella presenta un análisis que supera la lectura de la tradición y, desde su filosofía, denominada como pensamiento nuevo, esboza una ruptura con el idealismo, quebrantando la totalidad con la noción de infinito (nociones que encontrarán un eco evidente en el trabajo de Emmanuel Lévinas): infinitud como otredad incesante, que manifiesta, en el tiempo, la posibilidad de acceso a la eternidad y eternidad que se revela en la temporalidad.

El punto de partida de Rosenzweig en la exposición de La estrella es la confutación a la totalidad pensable, siendo que hay un resto que

2 "La visión (anti) filosófica y la visión religiosa son presentadas en un bella, simple y convincente prosa" [Trad. del autor].

3 "Si alguien ha producido una teoría de la revelación, en mi opinión, ese es Franz Rosenzweig, en la segunda parte de La estrella de la redención" [Trad. del autor]. 
excede a lo que puede ser pensado-demostrado, la razón no logra captar la totalidad y, por ende, está imposibilitada de confeccionar juicios cuya elaboración lógica permita una comprensión «omniamplectante» de lo asumido como totalidad desde la óptica idealista de la Modernidad. Rosenzweig, como apunta Navarrete (2015), fue influido por las tesis anti-historicistas de Hermann Cohen, el neokantiano. Asume que la nada penetra en la realidad y que ésta no se puede configurar de manera unidimensional y monolítica, dentro del enfoque de totalidad. En Cohen, según concibe Rosenzweig, se presenta una ruptura con la tradición idealista, específicamente con la concepción del pensamiento como condición incondicionada de la conciencia del ser, donde la nada es punto de partida (Bertolino, 2000).

Con este marco de comprensión-incomprensión plasmado de inicio, Rosenzweig, en La estrella, parte de tres elementos de los que nada se conoce. Estos tres elementos manifiestan la suma de experiencia-pensamiento. Estos tres elementos acaecen como idea, sin que puedan ser demostrados o argumentados pues exceden a la lógica. Lo anterior no implica que pueda derivarse, posteriormente a su acaecimiento, un tratamiento racional; sino que, en primer instancia, devienen como «facticidades alógicas», no producidas por la subjetividad, sino experimentadas como «ideas prevoluntarias». Son, pues, siguiendo la denominación de Ángel Garrido Maturano, en un artículo intitulado "El tiempo que acontece por sí mismo", meta-objetos a partir de un núcleo experiencial irracional” (2004). Éstos, son nombrados: Dios-Mundo-Hombre (Garrido, 2004: p. 101).

Desde la lectura del investigador Louis P. Blond (2010), Dr. de la Universidad de Edinburgh, La estrella se configura en tres secciones. La primera parte se asocia con la lógica filosófica y la adoración pagana. La segunda parte describe el mundo existencial empírico (revelación y la actual duración). En la parte tercera, se narra el camino hacia la redención: el futuro redimido mundo. En orden a mantener la crítica al idealismo, "la solución de Rosenzweig es deshabilitar la comprensión de toda la realidad, a partir del establecimiento de un desconocido más allá de la razón, lo que permite negar la totalidad 
racional" (2010: 32). De lo anterior, se asume una lectura de la realidad desde las «nadas» del pensamiento, Dios-Mundo-Hombre, como límites del pensamiento racional. Tales son, por ende, los puntos de partida en la elaboración de su tratado.

La problematización que deviene, en el desarrollo de La estrella se encuentra en el mecanismo por el cual estas realidades se relacionan. Si bien, los metaobjetos (tres elementos) no pueden compartirse ni transfigurarse uno en otro, por su condición formal («facticidad ideal»), pues se mantienen en su individualidad como diferente uno del otro en la subjetividad que los acoge de manera alógica. La manifestación se efectúa de manera dialógica, como acaecimiento en el proceso histórico. En suma, la subjetividad no produce los elementos, sino que, más bien, los recibe, dados en el mundo que, aparentemente, resulta ser comprensible por antonomasia, pero del cual la nada del mismo es su punto de partida. Según Rosenzweig, de Dios, del Mundo y del Hombre, no conocemos nada. Por lo tanto, su nada es nuestro punto de partida.

Dios ingresa en el tiempo del mundo y se revela como parte de su naturaleza. Esta revelación revela el mundo como un signo previo del poder de Dios sobre el ser humano. El ser humano, inspirado por el amor de Dios, no como amante sino como amado, irrumpe en vida -agente voluble activo.

Desde esta concepción, lejos de posturas que asumen a Dios cual agente externo al mundo, imposibilitado de cambio y fuera de todo tiempo, en La estrella se apela a un Dios que se manifiesta redimiendo constantemente al mundo, aunado a un ser humano que se descubre y que responde al llamado en la oración, noción que lejos de estar comprendida en un ámbito espiritualizado, se comprende como respuesta, según el casselense. Siguiendo la interpretación del fenomenólogo Garrido-Maturano:

Rezar significa, entonces, tener presente esta demanda de redención que alienta dentro de mi propio temporalizarme y que reencuentro cada vez que me topo con el otro hombre y con el mundo junto con los cuales soy" (Garrido, 2010: 166). 
Bernhard Casper, por su parte, lo pone en estos términos: "la oración en su propio acontecer se manifiesta como el tiempo de excepción en nuestro tiempo" (Casper en Garrido, 2010). Esta relacionalidad evidencia la comprensión de la eternidad por parte de Rosenzweig como el tiempo siempre renovado de Dios, si la redención es la re-configuración de Dios-mundo-hombre, un instante que vincula pasado, presente futuro, en la triada Creación-Revelación-Redención.

La reconfiguración, lejos de ser una manifestación de índole individual, se presenta como una acción de orden comunitario. La novedad en la interpretación de Rosenzweig radica en la eternización del «nosotros», como indica Giacomo Petrarca:

En este «nosotros», el individuo percibe su propio «yo». Dentro de ella, la comunidad se suspende, realmente único aquí, porque más allá de su separación, totalmente abierto a la humanidad entera, imagen de la eternidad (Petrarca, 2015: 20). ${ }^{4}$

El instante que permite la anticipación de la eternidad se genera en comunidad. Es epifanía. Se revela en el pueblo, re-configurando el pasado, el presente y futuro en el instante, irrumpiendo en la sincronicidad del tiempo del mundo, liberando al individuo y al pueblo del sí mismo y de la totalidad. Así lo lee Dussel. En el instante, se genera un culto al infinito como expresión de alegría ante la liberación, liberación de la sincronicidad, por lo que "La fiesta del Infinito es la alegría de la liberación. Por ello, nos dice Rosenzweig, los pueblos solo festejan y recuerdan los tiempos de su liberación" (Dussel, 1996: 127-128). La liberación no es una fuga de la sincronicidad, no es una salida del mundo; la libertad es la fiesta de la comunidad que deviene de la anticipación del futuro, como transformación de la eternidad en hoy, en el instante.

4 “Dans ce 'Nous' l'individu perçoit maintenant son propre 'moi'. À l'intérieur d'ellemême, la communauté est suspendue... car au-delà de sa séparation, complètement ouverte à l'humanité entière, image de l'éternité." [Trad. del autor]. 
El Día de Dios que irrumpe en el día del mundo

El Día de Dios representa la lectura de Rosenzweig a propósito de la temporalidad. Su propuesta parte de la triada Creación-RevelaciónRedención, que se correlacionan directamente con la triada DiosMundo-Hombre. El día de Dios, es el instante que vincula pasado, presente y futuro, estableciendo un lazo trans-histórico y anticipando la eternidad.

La lectura de Rosenzweig refuta la concepción lineal del tiempo que concluye con la muerte. A su vez, se distingue de la postura cristiana que asume la temporalidad de manera lineal a la espera de un salto dimensional, producto del advenimiento de Cristo (parousía), viviendo, por tanto, una sincronicidad a la espera de un llegar del más allá, vivir con un «aún no» entre los labios.

En la tradición cristiana, el «presente» figura como el «entre» que se tensa entre la Creación y el Juicio Final (el advenimiento). Así, la vida resulta vida del «entre»: tránsito fugaz, en medio de la eternidad. Incluso la Encarnación es un instante que se torna en época y posibilita un presente: "A partir del nacimiento de Cristo solo hay ya presente" (Rosenzweig, 2006: 403). Pero este instante es solo una escisión en la temporalidad. El Mundo es simplemente un acontecimiento que se lee a partir de la Creación, Encarnación y Regreso. Es una mirada siempre lineal, donde la temporalidad inicia su conteo en la Creación y culmina con el advenimiento, por segunda vez, de Cristo, lo que permite el acceso a la eternidad, cielo nuevo, tierra nueva.

A partir de la experiencia de la tradición judía, Rosenzweig expone un planteamiento de tiempo experimentado como simultaneidad. Así, en el «presente», el instante (ancho presente) vincula y re-configura el pasado-presente-futuro (Creación-Revelación-Redención). Dios no es un Deo abscondito: no se esconde o huye luego de lanzar los dados. Dios no crea y se oculta. De igual manera, no está únicamente en los instantes. En él no hay anticipación de la eternidad. La anticipación solo es posible en el hombre. Dios es presencia incesante. Para Rosenzweig, "el mundo no está aún acabado" (2006: 267), el futuro siempre existe en tanto futuro; no está fijo, en un devenir constante, 
que se anticipa en el día del mundo. Frente a este devenir, lo único que perdura es el Reino, que eternamente viene.

La comunidad atiende al Reino mediante la oración, que se comprende como acto que la apertura hacia más allá de la sincronicidad, uniendo pasado y presente. Es en la soledad de la oración, por tanto, que se logra atisbar y acceder al instante, a lo incesante de la redención que fulgura desde todo tiempo. La oración resulta, así, el ir más allá del horizonte de los sucesos, fuera de preparativos, sin premeditación, atendiendo a la fulguración, a lo incesante.

La estrella de Rosenzweig resplandece desde el pasado-presente-futuro. Sus destellos irrumpen desde la nada, como navaja que desgarra el tiempo cíclico y lacera el tiempo lineal. Lo infinito, como exterioridad, resuena en el mundo sincrónico y genera filtraciones que desmitifican la totalidad. Desde la otredad, resuena incesantemente el «en cada momento». Viviendo simultáneamente la eternidad en todos los tiempos, el mundo destinado a la vitalidad del Reino que desde el futuro viene eternamente. La eternidad, para Rosenzweig, "no es un tiempo larguísimo, sino un mañana que podría perfectamente ser también hoy. La eternidad es un porvenir que, sin dejar de ser porvenir, está sin embargo presente. La eternidad es un hoy que tiene conciencia de ser, no obstante, más que hoy" (Rosenzweig, 2006: 237).

\section{Palabras conclusivas}

A modo de conclusión, me atreveré a utilizar el lenguaje del casselense. Del tiempo, no sabemos nada. Pero este no saber es saber del tiempo. Es el principio de nuestro saber sobre éste. Es el principio, mas no el final. Si partimos del algo a la nada estaremos acometiendo el itinerario de los predecesores. Por tanto, partiremos de la nada hacia lo algo. Esto, a partir de los supuestos del Todo único y universal. Nuestra meta es un algo. El estatuto del tiempo, a partir de la lectura de La estrella de la redención.

A partir de La estrella, sobre el tiempo no podemos afirmar que sea un ente en sí, ni una propiedad de la vida constituida como ser 
finito; no podemos asumir que sea un constructo posibilitado a partir de la elaboración de una estructura lógica o tampoco que pueda limitarse a la consideración de pertenecer al a priori de nuestra intuición, presupuesto de las experiencias del mundo, como una especie de tapiz que en conjunto con el espacio permita acceder al mundo de la experiencia.

Del tiempo no se puede afirmar que sea un devenir intuido por la autoconciencia, manifestado de múltiples maneras en la Historia, como desarrollo de la idea absoluta. El tiempo no es resultado del ejercicio lógico del ser cognoscente. El tiempo no es un meta-objeto inscrito en el reino del sentido, que logra ser atisbado mediante referencias. El tiempo no se correlaciona directamente con el ser y ni el pensar.

La nada del tiempo comparece ante la conciencia en el día del mundo, antes de la conceptualización, del juego intelectivo sobre la categoría de tiempo. La vivencia recibe, hospeda y experimenta la temporalidad. La temporalidad se hace carne en el mundo de la vida, tomando no-conciencia de sí.

La subjetividad experimenta de modo meta-lógico la vivencia del tiempo y en su inevitable ejercicio racional procura tematizar la experiencia a partir de la deconstrucción de esquemas predispuestos. Suspendiendo los juicios de la conciencia, el tiempo se manifiesta en su desnudez; la eternización se presenta, a su vez, como la esencia del tiempo. La subjetividad, lejos de apresar el tiempo dentro de los límites de su mundo, que no son más que los límites de su razonamiento y de su lenguaje, puede percibir el incesante golpe de la exterioridad, atravesando el horizonte de comprensión sobre la temporalidad.

El tiempo es siempre eternidad. El Día de Dios, desprendido del lenguaje teológico de Rosenzweig, es un presente perpetuo donde la subjetividad, debido a su finitud, solo logra captar fragmentos. El tiempo sincrónico es el intento de entrelazar fragmentos, llevado a cabo por la subjetividad: relación de puntos dentro de una recta. La mirada subjetiva es infructuosa, pero, a su vez, logra recibir el llamado de la otredad, el resto, la extrañeza de otro modo de ser que permite anticipar (conocer meta-lógico) lo eterno. 
No hay tiempo como mera finitud, no hay un meta-tiempo fuera del tiempo. La realidad («mundo de la vida») no es un fragmento temporal que se encuentra escindiendo una eternidad: la eternidad es ahora. Los instantes están presentes. La subjetividad puede eternizarse a partir de los restos que aparecen como trazos de infinito en la Historia, y anticipar con los otros, en un nosotros, la eternidad. La subjetividad es finita, pero nosotros somos eternos.

\section{Referencias bibliográficas}

Balcarce, G. (2010). "Franz Rosenzweig y la anticipación de la eternidad”. Cuadernos de Filosofía (55): 117-140.

Batnitzky, L. (2000). Idolatry and Representation. New Jersey: Princeton University Press.

Bertolino, L. (2000). "La filosofía del nulla in Fran Rosenzweig". Annuario Filosofico (16): 257-287.

Blond, Louis. 2010. "Franz Rosenzweig: Homelessness in Time”. New German Critique Fall (37): pp27-58.

Casper, B. (1998). Das Ereignis des Betens. Grundlinien einer Hermeneutik des religiösen Geschenhens. Frieburg, München: Alber.

Dussel, E. (1996). Filosofía de la Liberación. Bogotá: Nueva América.

Eliade, M. (1954). Cosmos and History, The myth of the eternal return. New York: Harper Touchbooks.

Garrido-Maturano, Á. (2010). Ensayo sobre el sentido filosófico, cosmológico y religioso del tiempo. Buenos Aires: Biblos.

Garrido-Maturano, Á. (2004). “El tiempo que acontece por sí mismo”. Thémata (32): pp. 99-118.

Gershom, S. (2012). "On Franz Rosenzweig and His Familiarity with Kabbala Literature”. Naharaim $(6,1):$ 1-6.

Heidegger, M. (2012). Ser y tiempo, J.E. Rivera, trad. Madrid: Trotta.

Lucca, E. (2012). "Gershom Scholem on Franz Rosenzweig and the Kabbalah. Introduction to the Text". Naharaim, (6-1): pp. 7-19.

Lévinas, E. (2016). Totalidad e Infinito, M. García-Baró, trad. Salamanca: Sígueme. 
Navarrete, R. (2015). Franz Rosenzweig y la crisis del historicismo alemán. Pensamiento (71)256: pp.117-135.

Petrarca, G. (2015). “La communauté et le reste. Sur Franz Rosenzweig”. Les Cahiers Philosophiques de Strasbourg 1: pp. 9-28.

Rosenzweig, F. (1999). Understanding the Sick and the Healthy: $a$ view of World, Man and God, N. Glatzer, trad. Cambridge: Harvard University Press.

Rosenzweig, F. (2006). La estrella de la redención, M. García-Baró, trad. Salamanca: Sígueme.

Taub, E. (2011). "Universalidad y mesianismo: para una teología política desde el pensamiento de Hermann Cohen”. Revista Pléyade (8): pp. 85-102.

Toscano, J. (2014). "Rosenzweig: la temporalidad de la redención como principio teológico-político”. Areté 26 (1): pp. 53-76. 